\title{
SolarView: Georgia Solar Adoption in Context
}

\author{
Jacqueline Hettel Tidwell ${ }^{1, * \mathbb{D}}$, Abraham Tidwell ${ }^{2}$, Steffan Nelson ${ }^{1}$ and Marcus Hill ${ }^{1}$ \\ 1 Social Energy Atlas, Franklin College of Arts and Sciences, University of Georgia, Athens, GA 30602, USA; \\ steffan.nelson@uga.edu (S.N.); marcdh@uga.edu (M.H.) \\ 2 College of Agriculture and Environmental Sciences, University of Georgia, Athens, GA 30602, USA; \\ abraham.tidwell@uga.edu \\ * Correspondence: jacqueline.tidwell@uga.edu
}

Received: 4 November 2018 ; Accepted: 4 December 2018 ; Published: 7 December 2018

check for updates

\begin{abstract}
The local-national gap is a problem currently plaguing the adoption of emerging technologies targeted at resolving energy transition issues that are characterized by disparities in the adoption of innovations and policies on a local level in response to national policy implementation. These disparities reflect a complex system of technical, economic, social, political, and ecological factors linked to the perceptions held by communities and how they see energy development and national/global policy goals. This dataset is an attempt to bridge the local-national gap regarding solar PV adoption in the State of Georgia (U.S.) by aggregating variables from seven different publicly-available sources. The objective of this activity was to design a resource that would help researchers interested in the context underlying solar adoption on the local scale of governance (e.g., the county level). The SolarView database includes information necessary for informing policy-making activities such as solar installation information, a historical county zip code directory, county-level census data, housing value indexes, renewable energy incentive totals, PV rooftop suitability percentages, and utility rates. As this is a database from multiple sources, incomplete data entries are noted.
\end{abstract}

Dataset: doi:10.5281/zenodo.1477581.

Dataset License: CC-BY-NC-SA

Keywords: solar; technology adoption; demographics; mixed methods

\section{Summary}

The local-national gap is a problem currently plaguing the adoption of emerging technologies targeted at resolving energy transition issues that are characterized by disparities in the adoption of innovations and policies on a local level in response to national policy implementation. It is becoming increasingly apparent that individual communities do not necessarily share the same energy wants and needs with one another, and as noted in multiple studies of energy development projects [1,2], the alignment of value systems between energy sources and local needs plays a significant role in how, if at all, these sources are used [3].

Studies of the barriers and opportunities for implementing social innovations in the deployment of solar photovoltaics include a variety of qualitative, quantitative, and mixed methods approaches. These analyses are broadly concerned with identifying and reducing the barriers to adoption that occur at the level of policy-making (state or national), or within the decision-making processes of individuals. Nation-state-level analyses seek to impact how policy conversations pertaining to technology development, incentive structures, and other financial mechanisms enable sustainable energy transitions. Agent-based modeling studies $[4,5]$ leverage data gathered at the national scale, 
such as PV cost trends, solar irradiance, and incentive programs, to identify the capacity and location of future installations. A complimentary body of studies focuses on evaluating policy trends in high solar penetration areas (e.g., California) to generalize the possible impacts and limitations for other societies and institutional frameworks [6-9].

Individual and collective behavior analyses also seek to intercede in policy development. Where they differ is in the focus on identifying opportunities for social programs that enable knowledge sharing between individuals and communities. Individual adopter motivations [10], social networks [11,12], and perceptions of the technology [13-15] are the focus: these are elucidated through a series of surveys, semi-structured interviewing, and in some cases, ethnographic analysis. A key result from this body of work is the recognition that non-financial factors such as peer effects and the perception of self as an innovator [16] also drive when and how people adopt solar.

Nevertheless, gaps persist in our understanding of the disparities between national policy conversations about solar adoption and local action towards these goals. Known as the "local-national gap," this burgeoning area of research seeks to establish a space for national policy analyses and studies of individual motivations with community-level dynamics. Wüstenhagen, Wolsink, and Burer [17] noted that societal acceptance of energy technologies such as solar depends on factors such as socio-political acceptance, community acceptance, and market acceptance. These factors highlight that communities respond to new technologies in complex ways that belie perceptions of pro- and anti-innovation communities (NIMBYism). Batel and Devine-Wright [18] and Hess et al. [19] further posited that redressing the incoherence between national and local trends will require examining how actors independently and collectively interact and make decisions at scales ranging from individual communities to national action.

As described in Tidwell, Tidwell, and Nelson [20], there is a state within the United States of America that proves to be an interesting case study for investigating issues of local adoption of national renewable energy policy: Georgia. The Energy Information Administration positions Georgia as a leader in biomass energy production and an emerging space for the deployment of photovoltaic solar in the utility, commercial, and residential sectors [21]. Its status as an emergent space for PV solar is reflective of the perceived high potential for solar energy in Georgia in terms of solar insolation, it having some of the highest in the southeastern United States (Figure 1).

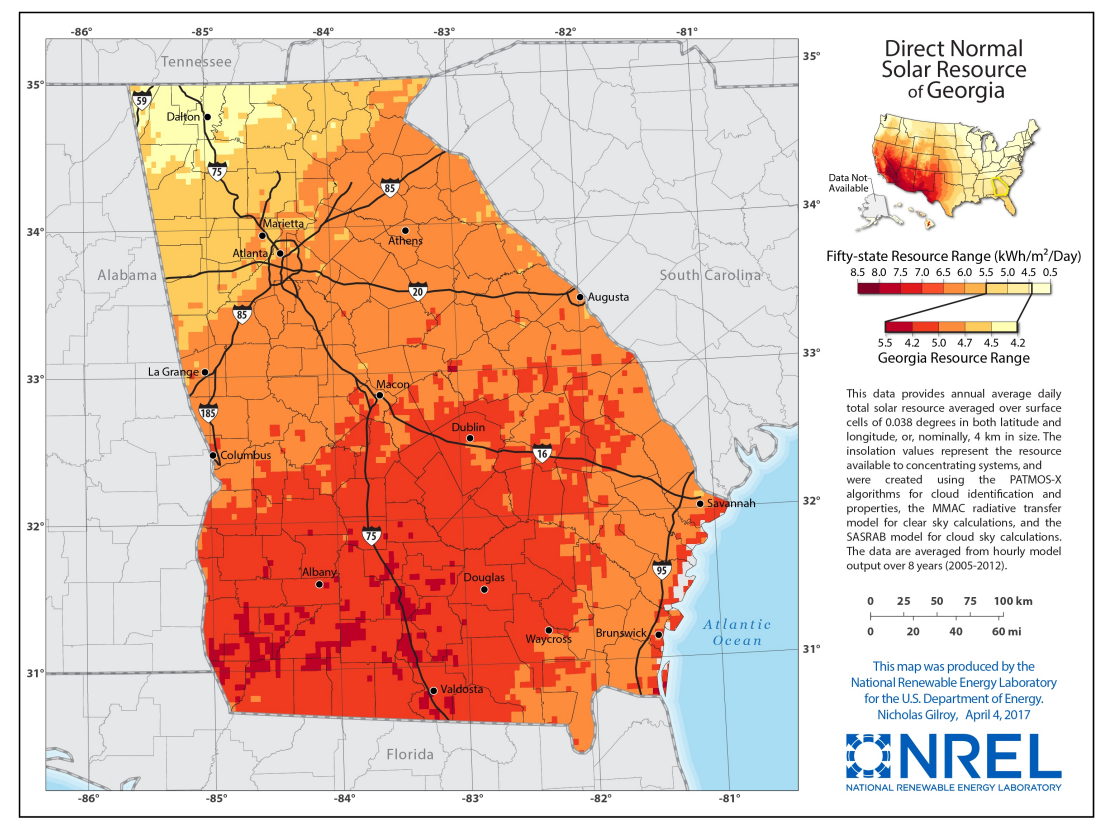

Figure 1. Solar irradiance map of the State of Georgia [22]. 
As a result of the size of the Georgian economy (ninth in the country by gross domestic product) and its existing energy system characteristics, Georgia is posited to be one of the states with the highest potential for solar deployment [23]. Recent trends in solar adoption seem to reflect these analyses.

Between 2017 and 2018, total net generation from solar photovoltaic rose from $22^{\text {nd }}$ in the nation [24] to ninth [21], moving Georgia from laggard to leader in solar power production [25]. Policy changes, including the Solar Power Free-Market Financing Act of 2015, have opened possibilities for integrating solar from third-party producers despite the lack of net metering policies or a renewable portfolio standard. Despite this seemingly positive uptake in energy generation through solar-powered technologies, a closer look locally indicates that the primary driving force is the integration of several utility and commercial-scale solar facilities. In 2018, Georgia ranked $37^{\text {th }}$ in power generated from residential PV solar, making it the lowest ranked state amongst the top ten in total PV solar energy production. Despite recent increases in the annual generation of electricity from solar installations in the State of Georgia — primarily a result of new utility-scale installations [21] — there is still a significant amount of potential for solar technology adoption for Georgia (see Table 1 [26]).

Table 1. Georgia energy data solar electric installations' summary.

\begin{tabular}{cccc}
\hline Use Sector & Number of Installations & Capacity & Annual Generation \\
\hline Residential & 1046 & $5822.99 \mathrm{~kW}$ & $8,128,855.02 \mathrm{kWh}$ \\
Non-Residential & 599 & $52,755.53 \mathrm{~kW}$ & $74,278,797.37 \mathrm{kWh}$ \\
Utility & 235 & $1,250,862.51 \mathrm{~kW}$ & $1,873,396,033.13 \mathrm{kWh}$ \\
\hline
\end{tabular}

One might wonder how a state positioned for high technical potential could have such low levels of adoption.

Respecting the complex interactions that exist within the local-national gap requires an eye towards understanding the multi-modal flows of information that are attuned to local policy-making conditions. The Social Energy Atlas, a program funded by the United States Department of Energy Solar Energy Technology Office, leverages large-scale qualitative and quantitative data analysis for examining why residents of the State of Georgia do or do not adopt rooftop photovoltaic solar [27]. The primary objective of this work is to develop more effective policy and programming to bridge the local-national gap in Georgia, through large-scale analysis of the stories people array when making such decisions about energy.

To address the limitation of existing adoption trend datasets at the scale of local governance (e.g., county governments), this data descriptor for SolarView, a web application designed by the Social Energy Atlas (see Figure 2), depicts how the aggregation of seven independent databases was conducted, so as to afford the Social Energy Atlas the ability to contextualize solar technology adoption at a local level of scale through the analysis of quantitative data for the State of Georgia, U.S., and demonstrate the complexity systems that are currently giving rise to significant disparity in adoption practices in this state using Gini coefficient calculations [20]. 


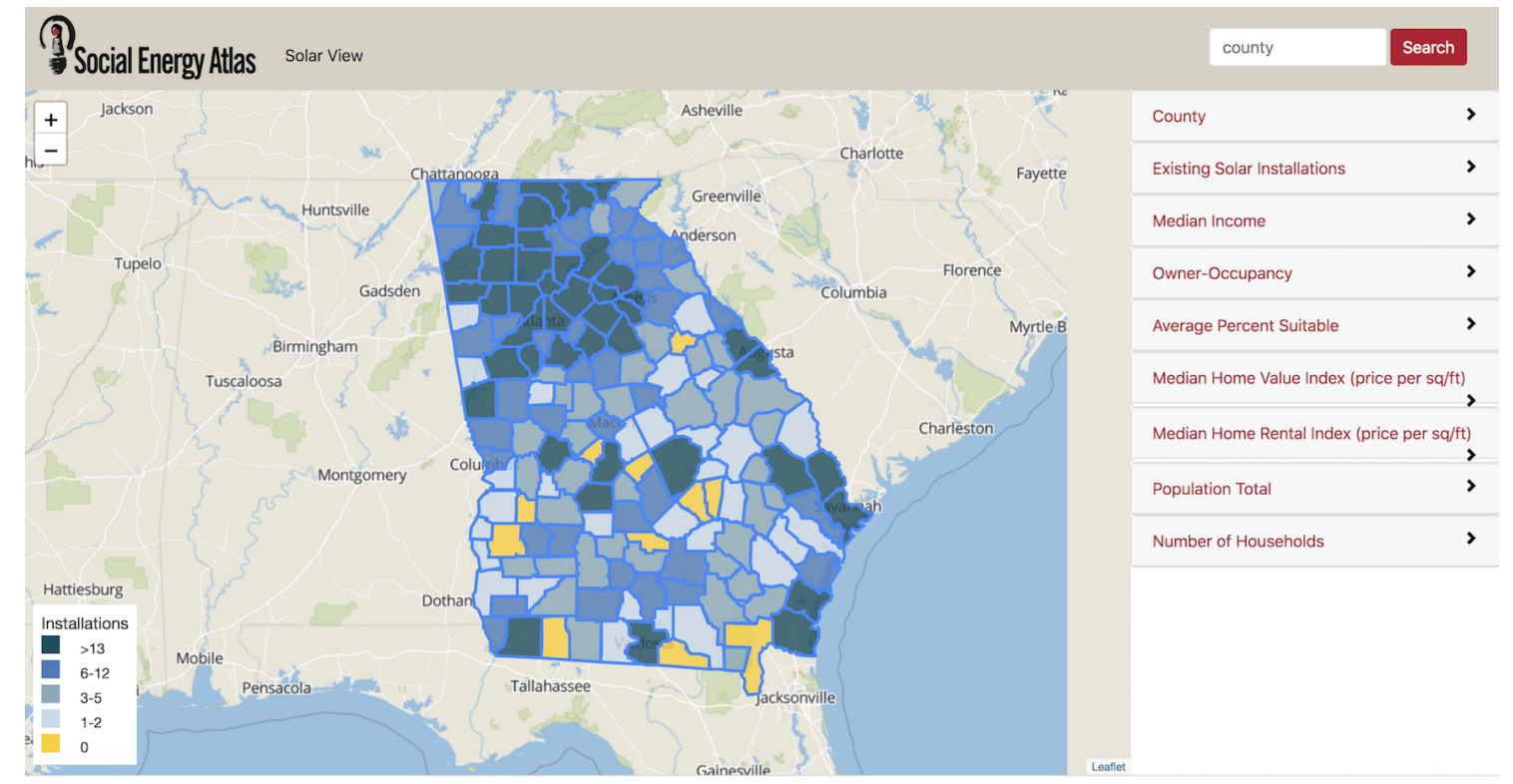

Figure 2. The Social Energy Atlas SolarView web application provides a dynamic experience for users interested in visually searching and experiencing patterns in Georgia (U.S.) solar adoption data.

The rest of the paper seeks to describe the dataset that was produced during the first phase of the Social Energy Atlas' research activities, as well as how it was brought together. In Section 2, a detailed description of the data comprising SolarView is provided. Section 3 provides the methods that were employed for curating and reusing the data. Finally, this data descriptor ends with Section 4, detailing notes for users of this database going forward.

\section{Data Description}

The data contained within the Supplementary Materials provides a contextually-focused perspective on solar adoption in the State of Georgia, U.S., at the county level and is comprised of nine relational CSV files. While currently, there are no solar installation data points for 11 of Georgia's 159 counties, this dataset does include contextual data that have been curated for every county. Descriptions of the variables included in the dataset are provided below, while justifications for the curation of this dataset from each data source can be found in Section 3.

\subsection{File Architecture}

The Georgia SolarView dataset is a relational database. The .csv files described in this section are related to one another through either zip code or Federal Information Processing Standard (FIPS) ID.

A README file and a copy of Figure 3 are included in the data archive as well. 


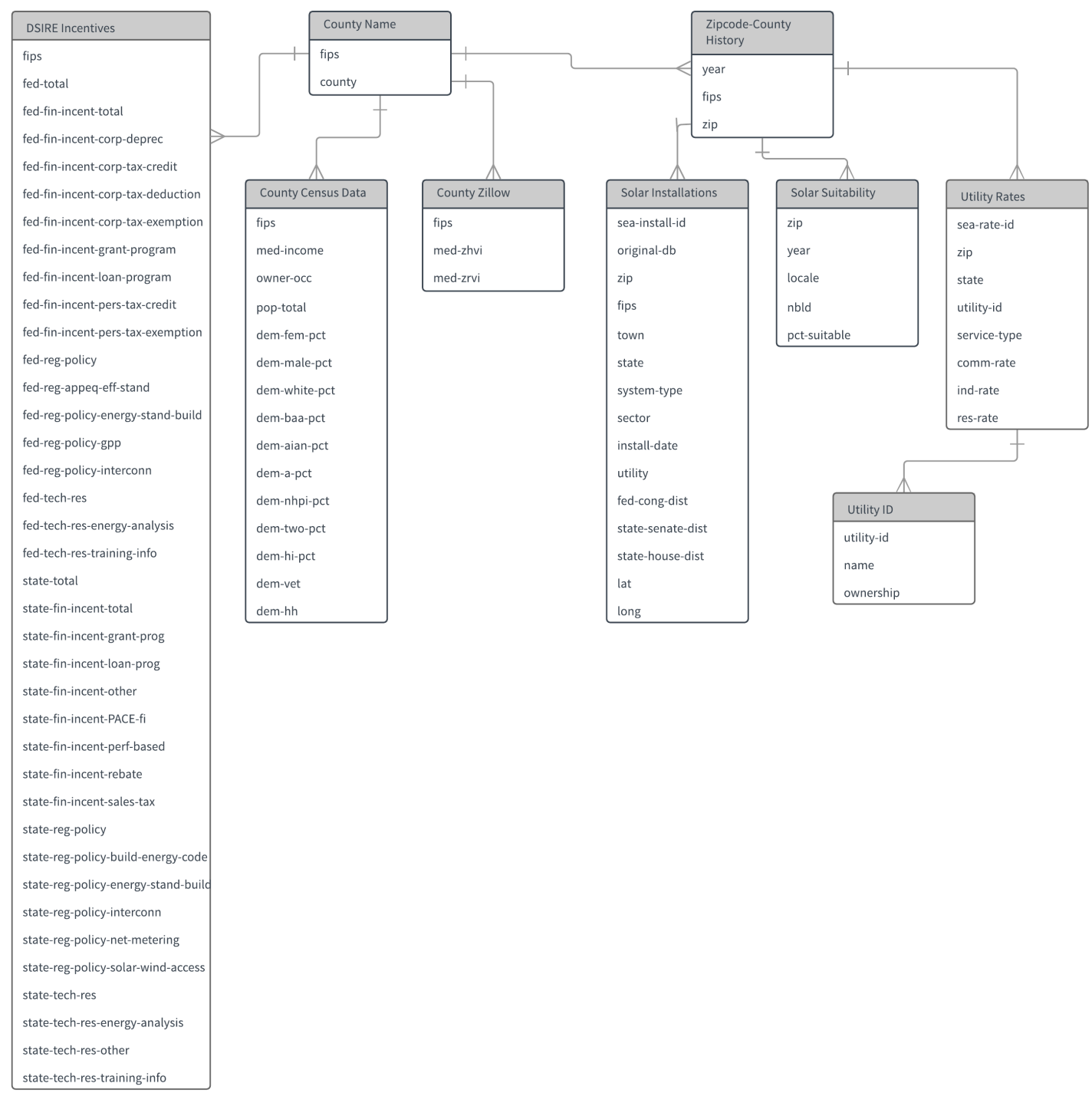

Figure 3. This figure is an entity relationship diagram depicting the relationships between all of the .csv files for this dataset that are described in Tables 1-8.

\subsection{County Identification}

The primary variable upon which this dataset is organized is the FIPS code for each county within the State of Georgia. The data within county-name.csv are the basis upon which the entire database is organized.

\subsection{Historical County Zip Code Directory}

Zip codes, while useful to many social scientists, are a dynamic class of variables constantly being added to, changed, and realigned to different counties per the needs of the U.S. Postal Service [28]. Thus, a historical directory of zip codes was determined to be necessary for this project, was included for the years 2010-2018, and can be found in sea-zipcode-county.csv. 
Table 2. List of variables included in sea-zipcode-county.csv.

\begin{tabular}{cc}
\hline Variable & Description \\
\hline sea-zip-id & Unique ID for zip code entries \\
zip & Zip code \\
fips & FIPScode for each county \\
year & Year for which a zip code and county relationship is valid \\
\hline
\end{tabular}

\subsection{Solar Installation Data}

For each documented solar installation in the State of Georgia, a series of characteristics was included as part of the data analysis for better understanding the context underlying solar technology adoption on the county level.

Table 3. List of variables included in sea-solar-installations.csv.

\begin{tabular}{cc}
\hline Variable & Description \\
\hline sea-install-id & Unique ID for identifying originating data source \\
zipcode & Zip code for solar installation \\
fips & County FIPS ID of solar installation \\
town & Town or municipality of solar installation \\
state & State of solar installation location \\
system-type & Type of solar system for the installation \\
sector & Sector type for installation location: e.g., residential or utility \\
install-date & Date of installation \\
utility & Utility of the installation \\
federal-cong-dist & Federal Congressional District of installation \\
state-senate-dist & State Senate District of installation \\
state-house-dist & Federal House of Representatives District of installation \\
lat & Latitude of solar installation (key) \\
long & Longitude of solar installation (key) \\
\hline
\end{tabular}

As these data were curated from multiple outside sources, their completeness is not guaranteed. Refer to Section 3.2 for details regarding data verification for this table.

\subsection{Solar Rooftop Suitability}

Data are also included for better understanding the disparity in the presence of solar installations in the State of Georgia and that relationship in with the degree of rooftop suitability available for each county.

Table 4. List of variables included in sea-solar-suitability.csv.

\begin{tabular}{|c|c|}
\hline Variable & Description \\
\hline zipcode & Zip code for each rooftop suitability estimation \\
\hline locale & Classification of the nature of the area: e.g., large suburb or fringe rural areas \\
\hline nbld & Number of existing rooftops identified in that location and included in the estimation \\
\hline pct-suitable & Estimated percent suitability of existing rooftops for PV \\
\hline
\end{tabular}

\subsection{County Demographics}

A selected number of U.S. Census Bureau demographic variables were also included for contextual analysis. In addition to the county FIPS ID codes, critical contextual data that were necessary for establishing relationships to socioeconomic status (median income), housing status (percentage of owner occupancy), population density (total population), and race (estimated percentage by racial group) were selected for inclusion in the SolarView database. 
Table 5. List of variables included in sea-county-census.csv.

\begin{tabular}{cc}
\hline Variable & Description \\
\hline fips & County FIPS ID \\
med-income & $\begin{array}{r}\text { Median income for the county } \\
\text { owner-occ } \\
\text { pop-total }\end{array}$ \\
dem-fem-pct & $\begin{array}{r}\text { Estimated percentage of homes occupied by its owner for the county } \\
\text { Total estimated population for the county }\end{array}$ \\
dem-male-pct & Estimated percentage of female residents in the county \\
dem-white-pct & Estimated percentage of male residents in the county \\
dem-baa-pct & Estimated percentage of white residents in the county \\
dem-aian-pct & Estimated percentage of American Indian or Alaskan Native residents in the county \\
dem-a-pct & Estimated percentage of Asian residents in the county \\
dem-nhpi-pct & Estimated percentage of Native Hawaiian or Pacific Islander residents in the county \\
dem-two-pct & Estimated percentage of residents identifying as being of two or more races in the county \\
dem-hl-pct & Estimated percentage of Hispanic or Latino residents in the county \\
dem-vet & Estimated number of veterans residing in the county \\
dem-hh & Estimated number of households in the county \\
\hline
\end{tabular}

\subsection{Zillow Indexes}

Median home value and rental value indexes are also provided for analysis. Due to the rural nature of Georgia and limited number of available data points for public sales and rental information in some counties, there are not values for all of Georgia's 159 counties. Refer to Section 3.2 for details regarding data verification for this table.

Table 6. List of variables included in sea-county-zillow.csv.

\begin{tabular}{cc}
\hline Variable & Description \\
\hline fips & County FIPS ID \\
med-zhvi & Median Zillow Home Value Index \\
med-zrvi & Median Zillow Rental Value Index \\
\hline
\end{tabular}

\subsection{Renewable Energy Incentives}

For each county, there are varying levels of renewable energy incentives documented as being available. The number of active incentives by type are provided in sea-dsire-incentives.csv. 
Table 7. List of variables included in sea-dsire-incentives.csv.

\begin{tabular}{|c|c|}
\hline Variable & Description \\
\hline fips & County FIPS ID \\
\hline fed-total & Total number of federal incentives \\
\hline fed-fin-incent-total & Total number of federal financial incentives \\
\hline fed-fin-incent-corp-tax-credit & Number of federal corporate tax credit financial incentives \\
\hline fed-fin-incent-corp-tax-deduction & Number of federal corporate tax deduction financial incentives \\
\hline fed-fin-incent-corp-tax-exemption & Number of federal corporate tax exemption financial incentives \\
\hline fed-fin-incent-pers-tax-credit & Number of federal personal tax credit financial incentives \\
\hline fed-fin-incent-pers-tax-exemption & Number of federal personal tax exemption financial incentives \\
\hline fed-reg-policy & Total number of federal regulatory policies \\
\hline fed-reg-policy-appeq-eff-stand & Number of federal appliance and equipment efficiency standard regulatory policies \\
\hline fed-reg-policy-energy-stand-build & Number of federal energy standards for public buildings' regulatory policies \\
\hline fed-reg-policy-gpp & Number of federal green power purchasing regulatory policies \\
\hline fed-reg-policy-interconn & Number of federal interconnection regulatory policies \\
\hline state-fin-incent-total & Total number of state financial incentives \\
\hline state-fin-incent-grant-prog & Number of state grant program financial incentives \\
\hline state-fin-incent-loan-prog & Number of state loan program financial incentives \\
\hline state-fin-incent-other & Number of state other financial incentives \\
\hline state-fin-incent-PACE-fi & Number of state Property Assessed Clean Energy (PACE) Financing programs financing financial incentives \\
\hline state-fin-incent-perf-based & Number of state performance-based financial incentives \\
\hline state-fin-incent-rebate & Number of state rebate financial incentives \\
\hline state-fin-incent-sales-tax & Number of state sales tax financial incentives \\
\hline state-reg-policy & Total number of state regulatory policies \\
\hline state-reg-policy-build-energy-code & Number of state building energy code regulatory policies \\
\hline state-reg-policy-energy-stand-build & Number of state energy standards for public buildings' regulatory policies \\
\hline state-reg-policy-interconn & Number of state interconnection regulatory policies \\
\hline state-reg-policy-net-metering & Number of state building net metering regulatory policies \\
\hline
\end{tabular}

\subsection{Electric Utilities}

As many diverse local governance structures the State of Georgia has, it also has a great number of utilities that help to provide infrastructural resources across the state. There are two files that help to provide information about the utility landscape of this state: a table listing the names and ownership structures of each utility (See Table 8) and a table listing the utility rates by zip code for the state (See Table 9).

Table 8. List of variables included in sea-utility-id.csv.

\begin{tabular}{cc}
\hline Variable & Description \\
\hline utility-id & Unique identifier for each utility \\
name & Utility name \\
ownership & Ownership type \\
\hline
\end{tabular}

Table 9. List of variables included in sea-utility-rates.csv.

\begin{tabular}{cc}
\hline Variable & Description \\
\hline sea-rate-id & Unique identifier for the utility rate for each zip code \\
year & Year for which the rate is provided \\
zip & Zip code for each utility rate \\
utility-id & Unique identifier for each utility \\
service-type & Type of rate service \\
comm-rate & Commercial rate per $\mathrm{kWh}$ \\
ind-rate & Industry rate per $\mathrm{kWh}$ \\
res-rate & Residential rate per $\mathrm{kWh}$ \\
\hline
\end{tabular}




\section{Methods}

The main methods applied to collect and treat, as well as to use and reuse the data are given here, as well as notes on the validation and curation techniques applied and on the data quality, noise, etc.

\subsection{Data Sources}

The SolarView database is an aggregation of seven independent data sources that each provide an important aspect of solar adoption at the county-level in Georgia, U.S.:

1. Georgia Energy Data Solar Map [26]

2. Open PV Project [29]

3. PV-Suitable Rooftop Resources [30]

4. American Community Survey (2016) [31]

5. Zillow Research Data [32]

6. DSIRE Programs [33]

7. U.S. Electric Utility Companies and Rates [34]

All available entries that correlated with Georgia's 159 counties and the zip codes within them were marked for inclusion in the aggregated dataset.

Not all variables within each of the seven databases were included for SolarView, however. Only those variables that were determined to be of imminent or future interest to the Social Energy Atlas' focus on understanding local Georgia perspectives of solar technology adoption were retained. Once the variables of interest for SolarView had been identified, three independent queries were performed on the seven databases and returned the same number of results each time. Convinced of the validity of these outputs, the contents of those queries were then verified for completeness.

In order to determine if the data comprising the SolarView database were complete, this was verified in two ways: first, by importing them on a Drupal CMS that was configured according to the relationships described in Figure 1 and, secondly, by flattening all of the data and parsing them through an Apache SOLR 6.6 indexer. Through this process, it was confirmed that several of the data streams comprising the SolarView aggregated database were incomplete in nature; an observation that was expected by the research team.

\subsection{Dataset Verification}

First of all, all of the solar installations in the SolarView database were collected from two different sources: Southface's Georgia Energy Data Map and the National Renewable Energy Laboratory's Open $P V$ Dataset [26,29]. These two sources have similar, but yet different, metadata systems. The Georgia Energy Data Map had a more comprehensive metadata standard, so the decision was made to use its variables so as not to lose future information that might be useful. Thus, the following variables for sea-solar-installations.csv were incomplete for one or more data points: zipcode (1), town (40), utility (1544), federal-cong-dist (1380), state-senate-dist (1380), state-house-dist (1380), lat (22), and long (22).

It was also determined that data were incomplete for the file labeled sea-county-zillow.csv. Zillow uses a combination of data points such as physical characteristics of the home, prior sales history, tax assessments, and geographic location to estimate sales prices using a proprietary statistical model that is backed by machine learning processes [35]. The resulting home sales value or rental value prices are an estimation based on the patterns they observe in the data. As a result, Zillow is often unable to calculate prices for areas in which they have a statistically limited number of data points. For Georgia's 159 counties that are described in the SolarView database, there are 75 counties for which no Zillow Home Value Index is available and 42 counties for which no Zillow Rental Value Index data are available. 


\section{User Notes}

The data can be visualized and viewed through a faceted search provided through the Social Energy Atlas SolarView web portal http:/ / sea.galib.uga.edu/solarview. This node.JS GIS application is powered by an Apache Solr index that dynamically visualizes the number of installations per county based on contextual filtering (see Figure 2). The data themselves can be accessed at https://github.com/socialenergy-atlas/solarview-data.

Though, as noted in [20], the political influence of Georgia's county governments is significant when compared to other parts of the United States, the opportunities derived from similar datasets and analyses could influence other relevant scales of governance (e.g., municipal governments seeking local energy control, like the city of Boulder, Colorado). For example, this and similar information gathered and parsed at the county level can aid individual local governments and those seeking to create transparency around energy decision-making in clearly-defining barriers and opportunities for impacting local policy. Furthermore, a county-specific distribution of solar disparities can provide context for future state-level policy discussions concerning regional equity in energy access, economic opportunities for sustainable development, and potentially, future region-specific solar incentive programs.

Author Contributions: Conceptualization: J.H.T.; methodology: J.H.T.; validation: J.H.T., M.H., S.N., and A.T.; investigation: J.H.T., S.T., M.H., and A.T.; data curation: J.H.T.; data verification: S.T. and M.H.; writing, original draft preparation: J.H.T.; writing, review and editing: J.H.T. and A.T.; project administration: J.H.T.; funding acquisition: J.H.T.

Funding: This project was funded by the U.S. Department of Energy's Solar Energy Technology Office, Award DE-EE0007664.

Acknowledgments: The authors would first like to acknowledge the support of the U.S. Department of Energy Solar Energy Technologies Office, without whom this work would not be possible. Moreover, they would like to acknowledge Southface for its work in managing and updating the Georgia Energy Data portal, from which most of the solar installation data were retrieved. We would also like to acknowledge the work of Steffan Nelson and Marcus Hill in migrating this dataset into the Social Energy Atlas SolarView web application.

Conflicts of Interest: The authors declare no conflict of interest.

\section{Abbreviations}

The following abbreviations are used in this manuscript:

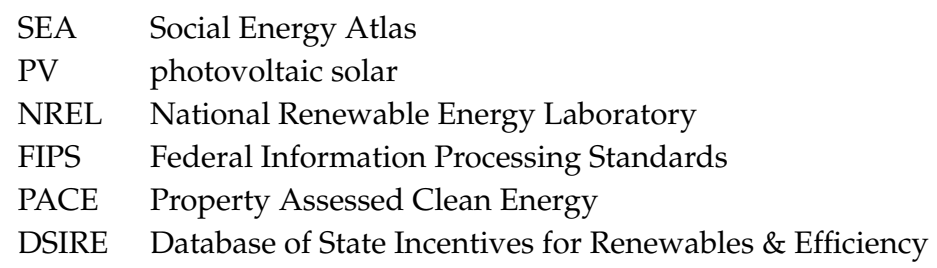

\section{References}

1. McKay, K. Socio-Cultural Dimensions of Cluster vs. Single Home Photovoltaic Solar Energy Systems in Rural Nepal. Sustainability 2010, 2, 494-504. [CrossRef]

2. Zhao, X.; Zhao, H.; Jiang, L.; Lu, C.; Xue, B. The Influence of Farmers' Livelihood Strategies on Household Energy Consumption in the Eastern Qinghai-Tibet Plateau, China. Sustainability 2018, 10, 1780. [CrossRef]

3. Sovacool, B. Exploring and Contextualizing Public Opposition to Renewable Electricity in the United States. Sustainability 2009, 1, 702-721. [CrossRef]

4. Denholm, P.; Drury, E.; Margolis, R. The Solar Deployment System (SolarDS) Model: Documentation and Sample Results (Technical Report No. NREL/TP-6A2-45832); National Renewable Energy Lab: Golden, CO, USA, 2009. Available online: https:/ / www.nrel.gov/docs/fy10osti/45832.pdf (accessed on 15 November 2018).

5. Zhang, H.; Vorobeychik, Y.; Letchford, J.; Lakkaraju, K. Data-drien agent-based modeling, with application to rooftop solar adoption. Auton. Agents Multi-Agent Syst. 2016, 30, 1023-1049. [CrossRef] 
6. Laird, F. Solar Energy, Technology Policy, and Institutional Values; Cambridge University Press: Cambridge, UK, 2001.

7. Del Río, P.; Mir-Artigues, P. Support for solar PV deployment in Spain: Some policy lessons. Renew. Sustain. Energy Rev. 2012, 16, 5557-5566. [CrossRef]

8. Hoppmann, J.; Huenteler, J.; Girod, B. Compulsive policy-making-The evolution of the German feed-in tariff system for solar photovoltaic power. Res. Policy 2014, 43, 1422-1441. [CrossRef]

9. Van Benthem, A.; Gillingham, K.; Sweeney, J. Learning-by-Doing and the Optimal Solar Policy in California. Energy J. 2008, 29, 131-151. [CrossRef]

10. Rai, V.; Reeves, D.C.; Margolis, R. Overcoming barriers and uncertainties in the adoption of residential solar PV. Renew. Energy 2016, 89, 498-505. [CrossRef]

11. Graziano, M.; Gillingham, K. Spatial patterns of solar photovoltaic system adoption: The influence of neighbors and the built environment. J. Econ. Geogr. 2015, 15, 815-839. [CrossRef]

12. Noll, D.; Dawes, C.; Rai, V. Solar Community Organizations and active peer effects in the adoption of residential PV. Energy Policy 2014, 67, 330-343. [CrossRef]

13. Faiers, A.; Neame, C. Consumer attitudes towards domestic solar power systems. Energy Policy 2006, 34, 1797-1806. [CrossRef]

14. Komendantova, N.; Patt, A.; Barras, L.; Battaglini, A. Perception of risks in renewable energy projects: The case of concentrated solar power in North Africa. Energy Policy 2012, 40, 103-109. [CrossRef]

15. Urpelainen, J.; Yoon, S. Solar home systems for rural India: Survey evidence on awareness and willingness to pay from Uttar Pradesh. Energy Sustain. Dev. 2015, 24, 70-78. [CrossRef]

16. Schelly, C. Residential solar electricity adoption: What motivates, and what matters? A case study of early adopters. Energy Res. Soc. Sci. 2014, 2, 183-191. [CrossRef]

17. Wüstenhagen, R.; Wolsink, M.; Bürer, M.J. Social acceptance of renewable energy innovation: An introduction to the concept. Energy Policy 2007, 35, 2683-2691. [CrossRef]

18. Batel, S.; Devine-Wright, P. A critical and empirical analysis of the national-local "gap" in public responses to large-scale energy infrastructures. J. Environ. Plan. Manag. 2015, 58, 1076-1095. [CrossRef]

19. Hess, D.J.; Mai, Q.D.; Skaggs, R.; Sudibjo, M. Local matters: Political opportunities, spatial scale, and support for green jobs policies. Environ. Innov. Soc. Trans. 2018, 26, 158-170. [CrossRef]

20. Tidwell, J.H.; Tidwell, A.; Nelson, S. Surveying the Solar Power Gap: Assessing the Spatial Distribution of Emerging Photovoltaic Solar Adoption in the State of Georgia, U.S.A. Sustainability 2018, 10, 4117. [CrossRef]

21. U.S. Energy Information Administration. Electric Power Monthly February 2018; U.S. Government Printing Office: Washington, DC, USA, 2018. Available online: https://www.eia.gov/electricity/monthly/archive/ february2018.pdf (accessed on 8 November 2018).

22. Direct Normal Solar Resource of Georgia. Available online: https://www.nrel.gov/gis/images/state-levelresource-maps/dni/Georgia-DNI-2017-01.jpg (accessed on 15 November 2018).

23. Croucher, M. Optimal Deployment of Solar Index. Electr. J. 2010, 23, 75-81. [CrossRef]

24. U.S. Energy Information Administration. Electric Power Monthly February 2017; U.S. Government Printing Office: Washington, DC, USA, 2017. Available online: https:/ / www.eia.gov/electricity/monthly/archive/ february2017.pdf (accessed on 8 November 2018).

25. Rojc, P. Georgia's Conservative Path to a Solar Power Boom. Planetizen. 2018. Available online: https: / / www.planetizen.com/news/2018/06/99370-georgias-conservative-path-solar-power-boom (accessed on 15 November 2018).

26. Georgia Energy Data. Available online: http://www.georgiaenergydata.org/solarmap (accessed on 25 July 2018).

27. Tidwell, J.H.; Tidwell, A.S.D. Energy ideals, visions, narratives, and rhetoric: Examining sociotechnical imaginaries theory and methodology in energy research. Energy Res. Soc. Sci. 2018, 39, 103-107. [CrossRef]

28. King, G. Ensuring the data-rich future of the social sciences. Science 2018, 331, 719-721. [CrossRef] [PubMed]

29. The Open PV Project. National Renewable Energy Laboratory. Available online: https://openpv.nrel.gov/ (accessed on 28 January 2018).

30. Phillips, C.; Melius, J.U.S. PV-Suitable Rooftop Resources. 2016. Available online: https:/ / www.osti.gov / biblio/1258436 (accessed on 28 January 2018). [CrossRef] 
31. United States Census Bureau. American Community Survey, 2010-2016 Five-Year Profiles. Generated by Jacqueline Hettel Tidwell. Using American FactFinder. Available online: https:/ / factfinder.census.gov / faces/nav/jsf/pages/index.xhtml (accessed on 15 January 2018).

32. Zillow Home Value Index Data 2018. Available online: http:/ / zillow.com/research/data (accessed on 15 January 2018).

33. DSIRE-Programs. Available online: http:/ / programs.dsireusa.org / system / program?fromSir=0\&state=GA (accessed on 15 January 2018).

34. U.S. Electric Utility Companies and Rates: Look-Up by Zipcode (2015). Available online: https:/ / catalog. data.gov / dataset/u-s-electric-utility-companies-and-rates-look-up-by-zipcode-2015-8c84b (accessed on 15 January 2018).

35. Zillow Research. Zillow Home Value Index: Methodology. Available online: https://www.zillow.com/ research/zhvi-methodology-6032/ (accessed on 20 October 2018).

(c) 2018 by the authors. Licensee MDPI, Basel, Switzerland. This article is an open access article distributed under the terms and conditions of the Creative Commons Attribution (CC BY) license (http:/ / creativecommons.org/licenses/by/4.0/). 